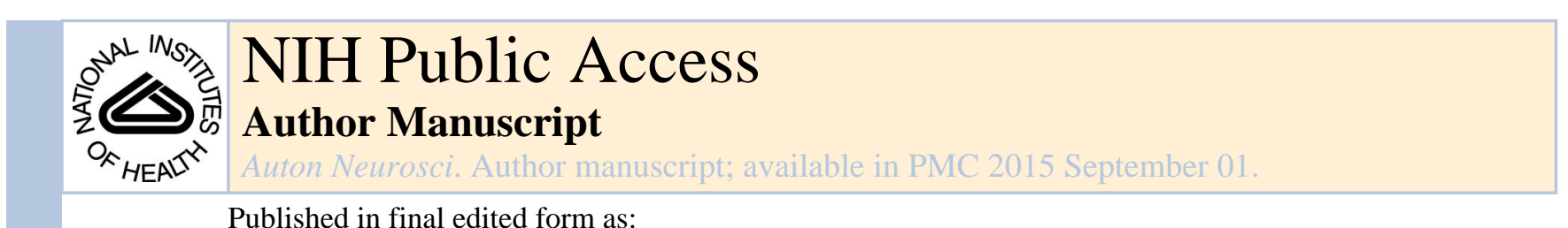

Published in final edited form as:

Auton Neurosci. 2014 September ; 184: 27-32. doi:10.1016/j.autneu.2014.06.004.

\title{
Non-Invasive Management of Vasovagal Syncope
}

\author{
Samuel T Coffin, MD ${ }^{1,2}$ and Satish R Raj, MD MSCI ${ }^{1,2,3}$ \\ ${ }^{1}$ Autonomic Dysfunction Center, Vanderbilt University School of Medicine \\ ${ }^{2}$ Department of Medicine, Vanderbilt University School of Medicine \\ ${ }^{3}$ Pharmacology, Vanderbilt University School of Medicine
}

\begin{abstract}
Vasovagal syncope (VVS) is a common disorder of the autonomic nervous system. While recurrent syncope can cause very impaired quality of life, the spells are not generally lifethreatening. Both non-pharmacological and pharmacological approaches can be used to treat patients. Conservative management with education, exercise and physical maneuvers, and aggressive volume repletion is adequate for controlling symptoms in most patients. Unfortunately, a minority of patients will continue to have recurrent syncope despite conservative therapy, and they may require medications. These could include vasopressor agents, beta-blockers, or neurohormonal agents. Some patients may require more aggressive device based therapy with pacemakers or radiofrequency ablation, which are emerging therapies for VVS. This paper will review non-procedure based treatments for VVS.
\end{abstract}

\section{Keywords}

syncope; vasovagal; treatment; non-pharmacological; medication

\section{Introduction}

VVS is an illness that is debilitating but treatable. It is a common cause of fainting. While most patients faint only infrequently, some patients faint frequently. Recurrent VVS is associated with a poor quality of life (Rose, Koshman, Spreng, \& Sheldon, 2000) that can be improved with treatments that decrease the burden of syncope.(Sheldon, Koshman, Wilson, Kieser, \& Rose, 1998)

(C) 2014 Elsevier B.V. All rights reserved.

Corresponding Author \& Address for Reprints: Satish R. Raj MD MSCI, Autonomic Dysfunction Center, Division of Clinical Pharmacology, Department of Medicine, Vanderbilt University School of Medicine, AA3228 Medical Center North, $116121^{\text {st }}$ Avenue South, Nashville, TN, 37232-2195, USA, Tel. 615-343-3649, Fax 615-343-8649, satish.raj@ vanderbilt.edu.

Publisher's Disclaimer: This is a PDF file of an unedited manuscript that has been accepted for publication. As a service to our customers we are providing this early version of the manuscript. The manuscript will undergo copyediting, typesetting, and review of the resulting proof before it is published in its final citable form. Please note that during the production process errors may be discovered which could affect the content, and all legal disclaimers that apply to the journal pertain.

Conflicts of Interest - None 
The most commonly used pathophysiological model for VVS was first described by Edward P Sharpey-Shafer of St. Thomas' Hospital in London, UK.(SHARPEY-SCHAFER, 1956) In gravity-dependent vasovagal syncope, the blood pooling that results from upright posture leads to relative central volume depletion and reduced cardiac preload. In order to maintain blood pressure, there is a baroreceptor-mediated increase in sympathetic nervous system tone, with a resultant increase in cardiac contractility. The high contractility, combined with under-filled ventricles, can be sensed as excessive by cardiac mechanoreceptors. This then leads to a baroreceptor-mediated sudden increase in parasympathetic tone and withdrawal of sympathetic tone. VVS patients can then experience bradycardia or periods of asystole, and/or vasodilation or venodilation.

The common triggers include prolonged sitting or standing (upright posture) or the activation of large muscles via a reduction in cardiac preload. Cortical triggers such as anxiety (such as with blood exposure), severe emotion or pain can also trigger a VVS response, likely by direct actions on the medulla. These triggers are common, "everyday" experiences that can be difficult to avoid, and this can lead to recurrent VVS spells. These spells can also cause significant injury in 5\% of cases and can lead to significantly impaired quality of life.(Bartoletti et al., 2008; van Dijk et al., 2007)

Fortunately, there are a variety of simple treatments available to decrease the frequency of these episodes. The treatment of VVS generally involves layered, synergistic therapies including lifestyle change, physical maneuvers, medical therapy, and when needed, implantable devices. (FIGURE 1) Non-pharmacologic therapy is generally cheap, easily accomplished, and effective in VVS patients. The vast majority of patients are responsive to conservative therapies including educating patients about VVS, reviewing common VVS triggers, physical maneuvers to perform when they are feeling unwell, and increased oral fluid intake (TABLE 1). In the few patients that do not respond adequately to these therapies, pharmacologic options are available (TABLE 2). Patient categories such as age and comorbidities (especially hypertension) become important when choosing potential medications for VVS. When considering treatment, communication with the patient is extremely important, as therapies often must be tailored to individual response. There is trial data to support the use of many of these therapies, although these trials vary in both design strength (randomized controlled trial vs. observational study) and study size. The recommendations that follow are based on both these trial data and on clinical experience.

Device therapies are also important for treatment-refractory VVS. These treatment options will be discussed elsewhere in another article in this Special Issue on Syncope (Solbiati \& Sheldon, 2014).

\section{Non-Pharmacological Treatment of VVS}

\section{Education}

A wide range of non-pharmacologic approaches are beneficial for the treatment of VVS (TABLE 1). Education, in particular, is a quite helpful and necessary initial strategy.(White, Sheldon, \& Ritchie, 2003) It is common for patients to fear that they are at an increased risk of having a myocardial infarction of even dying when suffering from VVS. An initial 
priority is to make sure the patient is aware that VVS is not a fatal illness.(Soteriades et al., 2002) Especially in younger patients, VVS almost always follows a benign course. An observational study noted that mortality in non-cardiovascular syncope patients age 60 years or older was 5 times higher than for patients younger than age 60 years, likely explained by comorbid disease.(Kapoor et al., 1986) Along with reassurance, we recommend patient education focused on etiology, management, natural history, maintaining appropriate hydration, and avoiding potential triggers. There are a wide range of stimuli that can trigger vasovagal episodes. Physical triggers, including prolonged standing or upright sitting, exposure to high temperatures, dehydration, coughing, and physical pain can be causative. Likewise, emotional triggers such as watching medical procedures, seeing or thinking about blood, and the sudden onset of extreme emotions, can be effective triggers.

Medical alert bracelets can also be useful. Depending on the frequency of VVS episodes, patients may have repeatedly been taken to the Emergency Department (ED) and have been subjected to expensive and unnecessary testing for other causes of syncope. With the simple addition of a bracelet, patients may be able to avoid recurring and unnecessary ED visits and iatrogenesis.

\section{Fluid and Salt Intake}

The initial treatment approach for VVS is to increase dietary intake of salt and water. Venous pooling reduces ventricular preload during a VVS episode. A small, double-blinded, placebo-controlled study showed that intake of salt and water expands intravascular volume, (El-Sayed \& Hainsworth, 1996) potentially increasing venous return during an episode. This recommendation, along with general education, is thought to result in significant improvement in the vast majority of patients with VVS. Despite almost universal use of this strategy, there is limited evidence in support of increased water and salt intake. Increased hydration improved orthostatic symptoms for short periods of time in a prospective randomized open study, but did not improve intolerance overall.(Bellard et al., 2007) This strategy can also be significantly limited by co-existing hypertension, heart failure, or renal failure.(El-Sayed \& Hainsworth, 1996) If not medically contraindicated, we recommend hydration with at least 2 liters of fluid a day. Augmented salt intake can be achieved through an increase in dietary salt intake or the use of $\mathrm{NaCl}$ tablets in patients who do not like the taste of salt.

A recent large observational study showed a significant decrease in syncope burden and traumatic syncope burden with a standardized education protocol.(Aydin et al., 2012) Patients were first informed about the benign nature of the condition, received information about the pathophysiology and probable triggers for the condition, were taught how to avoid potentially triggering situations, and were given motivation to drink at least 2 liters of water per day and to start regular physical activities. They were also taught to use isometric counter-pressure maneuvers and to adopt supine positions with lightheadedness or other symptoms. Education significantly reduced traumatic injuries and syncope recurrences in VVS patients. 


\section{Removing Offending Agents}

Any medications that could potentially worsen symptoms should be removed if possible.

Common agents that could worsen symptoms include diuretics (decreased preload), venodilators (decreased preload), and vasodilators (decreased afterload). Removing these medications can be extremely helpful in reducing episodes.

\section{Psychological and Emotional Distress}

Emotional distress is common in VVS and can be an extremely debilitating symptom for patients. Repeated episodes of syncope can lead to anxiety over possible injury, negative social consequences, or even dying. This can be quite distressing. Anxiety and psychosocial issues commonly related to recurrent VVS predicted non-response to other therapies for VVS in a prospective cohort study.(Flint, Baker, Freeston, \& Newton, 2009) Emotional distress can result from VVS and also be a trigger for VVS. In patients that suffer from significant anxiety or negative emotional states around their syncope, this should also be a target of therapy. This could involve a selective serotonin reuptake inhibitor, psychotherapy, or both.

\section{Exercise Training}

Once education and initial attempts to increase intravascular volume have been attempted, there are a wide range of physical treatment strategies and maneuvers that can help to improve VVS treatment. Exercise training was initially widely used after it was shown to increase blood volume and improve baroreceptor function in 2 observational studies on VVS patients.(Gardenghi et al., 2007; Sheldon, Morillo, \& Krahn, 2004) Patients in exercise studies would do both aerobic exercises as well as core strengthening exercises. Despite the physiologic findings, there are only weak data for this exercise strategy actually preventing syncope.(Gardenghi et al., 2007) Despite the lack of clear evidence of efficacy, exercise is often recommended in the treatment of VVS.

\section{Physical Countermeasures}

We recommend that our patients with VVS lie down as quickly as possible after the onset of the VVS prodrome. Despite the lack of trial data, clinical experience has shown this strategy highly effective at preventing injury from syncope and preventing an episode leading to frank syncope.

Isometric muscle contractions have been shown to increase cardiac output and arterial blood pressure (BP) while decreasing syncope occurrence in both non-randomized and randomized trials.(Krediet et al., 2005; van Dijk et al., 2005; van Dijk et al., 2006) The most effective maneuver combines leg crossing and buttocks clenching, but improvement can also occur with arm contractions (arm contractions may be preferred by patients for use due to ease and to avoid embarrassment in public situations). It is important to educate patients to avoid performing a simultaneous Valsalva maneuver, which could accelerate syncope by decreasing venous return. One way for the patient to avoid performing an accidental Valsalva maneuver is for them to ensure that they can talk while performing the muscletensing maneuver. These maneuvers are easy to learn, free of cost and significant side effects, and have a well-understood physiologic basis that both patients and physicians can 
easily understand. A limitation of muscle contraction strategies is that an adequate prodrome is required in order to allow a conscious patient to actually perform the maneuvers.

The Physical Counterpressure Manoeuvres Trial (PC Trial) addressed the use of these maneuvers in a multicenter, prospective, randomized controlled trial of the addition of these maneuvers to conventional therapy in affected patients. The study randomized 223 patients with recurrent VVS, and treatment arm patients were taught several counterpressure techniques and advised to hold a chosen maneuver for the maximum tolerated time or until symptoms disappeared. There was a 36\% relative risk reduction for syncope (among the largest seen in any randomized controlled trial for any type of VVS therapy) over an average of 14 months of follow-up. A limitation was that $35 \%$ of patients did not have a prodrome that was long enough to see a significant benefit.(van Dijk et al., 2006)

\section{Tilt Training}

"Tilt training", or recurrent exposure to tilt testing maneuvers, was developed after the observation that repeated tilt testing was associated with a decrease in positive results of later tilt testing. This led to the hypothesis that repeated tilt testing could increase peripheral sympathetic function. One trial repeated daily tilt tests with patients remaining in the hospital until the patient could tolerate the entire duration of the tilt table test, which could take several days.(Ector, Willems, Heidbuchel, \& Reybrouck, 2005) Prolonged inpatient hospital stays are increasingly hard to justify, so multiple studies have evaluated outpatient training (standing against a wall for 30 minutes [or until presyncopal symptoms began] x1-2 times per day), which have shown mixed results. While a randomized Chinese trial did suggest a benefit with outpatient tilt training,(Zeng, Ge, Zhang, Wang, \& Guo, 2008) the majority of trials reported no significant effect.(Foglia-Manzillo et al., 2004; On, Park, Huh, \& Kim, 2007; Tan et al., 2010) A recent observational registry trial suggested modest benefit, but only recommended outpatient tilt training in young patients with refractory VVS.(Jang et al., 2013) The efficacy of home training may be limited by poor compliance. In a randomized, controlled trial, Foglia-Manzillo et al. found that only $34 \%$ of patients performed all of the prescribed sessions, even with a short follow-up period.(FogliaManzillo et al., 2004) Given the concerns about modest efficacy and poor compliance, we do not routinely advise self-administered tilt training in our practice, and reserve it only for the most motivated VVS patients.

\section{Pharmacological Treatment of VVS}

Pharmacological therapy for VVS should be considered in patients in whom nonpharmacologic measures, including education, fluid intake, and physical countermeasures, have failed. Many pharmacological treatments exist for VVS, but none has shown significant effectiveness in large, randomized, controlled trials. In spite of this, clinical management of refractory and recurrent VVS in well-chosen patients can result in decreased symptom burden (TABLE 2). 


\section{Beta-blockers}

Animal studies have shown beta-receptor involvement in ventricular baroreceptor reflexes, resultant hypotension and bradycardia during isoproterenol-influenced tilt testing,(Sheldon \& Killam, 1992; Waxman, Yao, Cameron, Wald, \& Roseman, 1989) and the ability of betablockers to block the downstream effects of isoproterenol.(Sra et al., 1992) Based on this data, beta-blockers were widely tested in the treatment of VVS. Multiple small nonrandomized and prospective randomized trials of mainly beta-1 selective blockers showed mixed results.(Cohen et al., 1995; Flevari et al., 2002; Iskos, Dutton, Scheinman, \& Lurie, 1998; Mahanonda et al., 1995; Nair, Padder, Kutalek, \& Kantharia, 2004; Theodorakis et al., 2006) The Prevention of Syncope Trial (POST) was a large, randomized, placebocontrolled, double-blinded trial that determined the effectiveness of metoprolol in VVS over a 1 year treatment period. Metoprolol provided no overall benefit in "freedom from syncope" over the year when compared to placebo. The hazard ratio for metoprolol in patients $\geq 42$ years of age was 0.53 (95\% confidence interval [CI 95\%] 0.25 to 1.10), but in patients $<42$ years of age, the hazard ratio was 1.62 (CI 95\% 0.85 to 3.10).(Sheldon et al., 2006) When combined with a pooled cohort study, these results became more convincing with a hazard ratio of 0.52 (CI 95\% 0.27-1.01) in patients $\geq 42$ years of age compared with a ratio of 1.58 (CI 95\% 1.00-2.31) for patients <42 years of age.(Sheldon et al., 2012) These results suggest an age-dependent effect on syncope. This, in combination with beta-blocker therapy's status as one of the very few pharmacologic treatments that does not increase blood pressure, make beta-blockers a reasonable choice for older VVS patients with comorbid hypertension. POST V is a current randomized, placebo-controlled, double-blinded study powered to assess whether metoprolol is beneficial in older VVS patients ( $\geq 40$ years).

Another small randomized, double-blinded, tilt-based crossover study by Eldadah et al. suggested that propranolol may be the optimal beta-blocker to use in the treatment of VVS. (Eldadah et al., 2006) The beta-2 adrenergic blockade might counter the adrenalinemediated vasodilation at the time of syncope.

\section{Mineralocorticoids}

Fludrocortisone is a corticosteroid that has been fluorinated, increasing its selectivity in activating mineralocorticoid receptors. This leads to acute sodium and water retention along with potassium excretion into the urine. The hypothetical mechanism of benefit in VVS would be to increase intravascular volume and perhaps decrease the autonomic outflow brought on by triggering situations. Fludrocortisone is considered an addition to dietary salt and water expansion rather than mono-therapy for VVS. An early open-label, uncontrolled study showed that children had significantly fewer syncopal and presyncopal episodes while taking fludrocortisone.(Scott et al., 1995) However, a randomized, double-blinded, controlled study actually found more symptoms in children randomized to fludrocortisone than those in the placebo arm.(Salim \& Di Sessa, 2005) The Second Prevention of Syncope Trial (POST II) examined fludrocortisone in the treatment of adults with VVS.(Raj, Rose, Ritchie, \& Sheldon, 2006) POST II was the first randomized, double-blinded, placebocontrolled clinical trial using fludrocortisone. 211 patients were randomized to either placebo or fludrocortisone for 1 year. There was a trend toward benefit with a relative risk reduction of $26 \%$ ( $\mathrm{P}=0.066$ ).(Sheldon et al., 2011) Likely due to blood pressure constraints, 
the average age of the subjects skewed toward the young, with a mean age of 30 years and a maximum age of 46 years. Given this trend toward significance, we continue to utilize fludrocortisone in younger VVS patients. Hypertension can limit the use of fludrocortisone, especially in older VVS patients.

\section{Selective Serotonin Reuptake Inhibitors}

Serotonin is a neurotransmitter that is known to affect BP and heart rate via modulation of the central nervous system. Selective serotonin reuptake inhibitors (SSRIs) are known to cause postsynaptic serotonin receptor down-regulation in the brain stem. This downregulation in receptor density could potentially blunt a sympathetic withdrawal response to rapid increases in serotonin levels. Several studies have attempted to use SSRIs in the treatment of VVS. A randomized, double-blinded, placebo-controlled study of paroxetine in patients with recurrent VVS showed a reduction in syncope recurrence over 2 years from $53 \%$ with placebo to $18 \%$ with paroxetine.(Di Girolamo et al., 1999) In contrast,

Theodorakis et al. performed a randomized, placebo-controlled, double-blinded trial of fluoxetine (a different SSRI) and found that it was no more effective than placebo for the prevention of VVS.(Theodorakis et al., 2006) Overall, the literature does not convincingly show SSRIs to be effective in preventing VVS symptoms.

\section{Alpha-1 Agonists}

Midodrine has been used to affect peripheral alpha- 1 adrenergic activity via its active metabolite, which is an agonist at alpha-1 receptors. It is known to cause arteriolar constriction as well as venoconstriction, which increases peripheral vascular resistance and cardiac output. Trial data has shown that in the majority of patients with VVS, a moderate fall in cardiac output with coincident vasodilatation occurs during a syncopal event.(Fu, Verheyden, Wieling, \& Levine, 2012) A number of clinical studies have reported promising evidence for using midodrine to prevent VVS,(Kaufmann, Saadia, \& Voustianiouk, 2002; Perez-Lugones et al., 2001; Qingyou, Junbao, \& Chaoshu, 2006; Ward, Gray, Gilroy, \& Kenny, 1998) but they are not conclusive and are accompanied by a negative study. (Romme, van, Go-Schon, Reitsma, \& Wieling, 2011) The ongoing Prevention of Syncope Trial IV (POST IV), a randomized, placebo-controlled, double-blinded study, is assessing midodrine vs. placebo in patients with frequent syncopal episodes, with results expected in 2017.(Raj, Faris, McRae, \& Sheldon, 2012) Midodrine is generally well-tolerated at low doses, and remains a reasonable option in patients without significant hypertension. At higher doses, there are a number of potential side effects including supine hypertension, nausea, piloerection, urinary retention, rash, and scalp paresthesias that generally resolve with dose decrease. The frequency of dosing and compliance challenges, the necessity to avoid bedtime dosing, and the side effect profile may limit midodrine's utility in older VVS patients. In addition, midodrine is not available over much of Europe, and a trial on etilefrine (similar to midodrine) was negative.(Raviele et al., 1999)

\section{Norepinephrine Transporter Inhibitors}

Norepinephrine transporter (NET) inhibitors block reuptake of norepinephrine at sympathetic neuronal pre-synaptic terminals. This can lead to an increase in sympathetic 
tone in situations where norepinephrine is released, such as during orthostatic stress.(Lechin et al., 2006) This could block the triggering of the vasovagal reflex, as well as prevent the subsequent loss of sympathetic tone. Sheldon et al. recently performed a proof of concept test using sibutramine in a prospective dose-ranging study in the most extremely symptomatic and treatment-refractory patients. Out of 7 patients, 5 had significantly decreased syncopal spell frequency.(Sheldon, Ritchie, McRae, \& Raj, 2013) While more research is needed, NET inhibitors may represent a promising treatment for treatmentrefractory VVS patients.

\section{Other Medications}

There are several other medications that have been reported to have been used in the management of VVS, but are not used in our practice. Disopyramide is a sodium channel blocker with prominent anticholinergic effects on the heart. This could potentially modify the cardioinhibitory reflex seen in a vasovagal reaction and reduce VVS symptoms. Unfortunately, 2 studies of disopyramide have shown no significant benefit over placebo, and extracardiac anticholinergic side-effects (including dry mouth, constipation, urinary retention, or even agranulocytosis) can often limit the use of disopyramide. In occasional patients, disopyramide can have life-threatening proarrhythmic effects.

Yohimbine is an alpha-2 receptor antagonist (the opposite of clonidine). By blocking the negative feedback alpha-2 receptor, yohimbine can increase sympathoneural tone.

Yohimbine has been shown to be effective at preventing tilt-test-induced syncope in a prospective proof of concept study, (Mosqueda-Garcia et al., 1998) but clinical syncope data is lacking. Tolerance of yohimbine can be limited due to its symptomatic sympathetic activation, and it is no longer manufactured, so it is available only through compounding pharmacies.

\section{Summary}

VVS is a syndrome that is challenging to treat, and a multi-pronged strategy is usually required for effective symptom control. We present an algorithm that we have found to be clinically useful which is based on both clinical experience and objective study data. First line therapy for VVS is education about physiology and the benign course of the disease and a discussion of potential triggering situations or contributing medications. Early interventions should include encouragement of increased water and salt intake, and for the majority of patients who have a clear symptomatic prodrome, instructions to lie down or squat upon feeling prodromal symptoms. Physical counterpressure maneuvers should also be attempted during these prodromal periods.

If patients continue to faint, age and co-morbid conditions should guide choice of pharmacotherapy. In young, otherwise healthy patients, we recommend starting with fludrocortisone $0.1-0.2 \mathrm{mg}$ PO daily. In older patients or patients with hypertension, we recommend starting with metoprolol $25-50 \mathrm{mg}$ PO BID. If the syncopal episodes are very frequent, psychosocial stressors should be addressed and a psychotherapy referral should be considered. In truly treatment-refractory situations, midodrine or even sibutramine are reasonable choices, though randomized trial data for these medications are from small trials 
and the results are inconclusive. Patients often require a personalized treatment approach in order to adequately control symptoms. Several large randomized controlled trials are ongoing to help guide rational and effective pharmacotherapy of this challenging disorder.

\section{Acknowledgments}

Research Funding - Supported in part by NIH grants R01 HL102387, P01 HL56693, and UL1 TR000445 (Clinical and Translational Science Award).

\section{Reference List}

Aydin MA, Mortensen K, Salukhe TV, Wilke I, Ortak M, Drewitz I, et al. A standardized education protocol significantly reduces traumatic injuries and syncope recurrence: an observational study in 316 patients with vasovagal syncope. Europace. 2012; 14:410-415. [PubMed: 22048993]

Bartoletti A, Fabiani P, Bagnoli L, Cappelletti C, Cappellini M, Nappini G, et al. Physical injuries caused by a transient loss of consciousness: main clinical characteristics of patients and diagnostic contribution of carotid sinus massage. Eur Heart J. 2008; 29:618-624. [PubMed: 18086659]

Bellard E, Fortrat JO, Custaud MA, Victor J, Greenleaf J, Leftheriotis G. Increased hydration alone does not improve orthostatic tolerance in patients with neurocardiogenic syncope. Clin Auton Res. 2007; 17:99-105. [PubMed: 17464552]

Cohen MB, Snow JS, Grasso V, Lehnert L, Goldner BG, Jadonath RL, et al. Efficacy of pindolol for treatment of vasovagal syncope. Am Heart J. 1995; 130:786-790. [PubMed: 7572587]

Di Girolamo E, Di IC, Sabatini P, Leonzio L, Barbone C, Barsotti A. Effects of paroxetine hydrochloride, a selective serotonin reuptake inhibitor, on refractory vasovagal syncope: a randomized, double-blind, placebo-controlled study. J Am Coll Cardiol. 1999; 33:1227-1230. [PubMed: 10193720]

Ector H, Willems R, Heidbuchel H, Reybrouck T. Repeated tilt testing in patients with tilt-positive neurally mediated syncope. Europace. 2005; 7:628-633. [PubMed: 16216768]

El-Sayed H, Hainsworth R. Salt supplement increases plasma volume and orthostatic tolerance in patients with unexplained syncope. Heart. 1996; 75:134-140. [PubMed: 8673750]

Eldadah BA, Pechnik SL, Holmes CS, Moak JP, Saleem AM, Goldstein DS. Failure of propranolol to prevent tilt-evoked systemic vasodilatation, adrenaline release and neurocardiogenic syncope. Clin Sci (Lond). 2006; 111:209-216. [PubMed: 16634720]

Flevari P, Livanis EG, Theodorakis GN, Zarvalis E, Mesiskli T, Kremastinos DT. Vasovagal syncope: a prospective, randomized, crossover evaluation of the effect of propranolol, nadolol and placebo on syncope recurrence and patients' well-being. J Am Coll Cardiol. 2002; 40:499-504. [PubMed: 12142117]

Flint B, Baker C, Freeston M, Newton JL. Level of psychosocial impairment predicts early response to treatment in vasovagal syncope. Europace. 2009; 11:231-236. [PubMed: 19059994]

Foglia-Manzillo G, Giada F, Gaggioli G, Bartoletti A, Lolli G, Dinelli M, et al. Efficacy of tilt training in the treatment of neurally mediated syncope. A randomized study. Europace. 2004; 6:199-204. [PubMed: 15121070]

Fu Q, Verheyden B, Wieling W, Levine BD. Cardiac output and sympathetic vasoconstrictor responses during upright tilt to presyncope in healthy humans. J Physiol. 2012; 590:1839-1848. [PubMed: 22331415]

Gardenghi G, Rondon MU, Braga AM, Scanavacca MI, Negrao CE, Sosa E, et al. The effects of exercise training on arterial baroreflex sensitivity in neurally mediated syncope patients. Eur Heart J. 2007; 28:2749-2755. [PubMed: 17561494]

Gibbons RJ, Smith S, Antman E. American College of Cardiology/American Heart Association clinical practice guidelines: Part I: where do they come from? Circulation. 2003; 107:2979-2986. [PubMed: 12814985]

Iskos D, Dutton J, Scheinman MM, Lurie KG. Usefulness of pindolol in neurocardiogenic syncope. Am J Cardiol. 1998; 82:1121-4. A9. [PubMed: 9817494] 
Jang WJ, Yim HR, Lee SH, Park SJ, Kim JS, On YK. Prognosis after tilt training in patients with recurrent vasovagal syncope. Int J Cardiol. 2013; 168:4264-4265. [PubMed: 23642601]

Kapoor W, Snustad D, Peterson J, Wieand HS, Cha R, Karpf M. Syncope in the elderly. Am J Med. 1986; 80:419-428. [PubMed: 3953619]

Kaufmann H, Saadia D, Voustianiouk A. Midodrine in neurally mediated syncope: a double-blind, randomized, crossover study. Ann Neurol. 2002; 52:342-345. [PubMed: 12205647]

Krediet CT, de Bruin IG, Ganzeboom KS, Linzer M, van Lieshout JJ, Wieling W. Leg crossing, muscle tensing, squatting, and the crash position are effective against vasovagal reactions solely through increases in cardiac output. J Appl Physiol. 2005; 99:1697-1703. [PubMed: 16227457]

Lechin F, van der Dijs B, Hernandez G, Orozco B, Rodriguez S, Baez S. Neurochemical, neuroautonomic and neuropharmacological acute effects of sibutramine in healthy subjects. Neurotoxicology. 2006; 27:184-191. [PubMed: 16269176]

Mahanonda N, Bhuripanyo K, Kangkagate C, Wansanit K, Kulchot B, Nademanee K, et al. Randomized double-blind, placebo-controlled trial of oral atenolol in patients with unexplained syncope and positive upright tilt table test results. Am Heart J. 1995; 130:1250-1253. [PubMed: 7484777]

Mosqueda-Garcia R, Fernandez-Violante R, Tank J, Snell M, Cunningham G, Furlan R. Yohimbine in neurally mediated syncope. Pathophysiological implications. J Clin Invest. 1998; 102:1824-1830. [PubMed: 9819368]

Nair N, Padder FA, Kutalek SP, Kantharia BK. Usefulness of pindolol for treatment of neurocardiogenic syncope. Am J Cardiol. 2004; 94:1189-1191. [PubMed: 15518620]

On YK, Park J, Huh J, Kim JS. Is home orthostatic self-training effective in preventing neurally mediated syncope? Pacing Clin Electrophysiol. 2007; 30:638-643. [PubMed: 17461874]

Perez-Lugones A, Schweikert R, Pavia S, Sra J, Akhtar M, Jaeger F, et al. Usefulness of midodrine in patients with severely symptomatic neurocardiogenic syncope: a randomized control study. $\mathrm{J}$ Cardiovasc Electrophysiol. 2001; 12:935-938. [PubMed: 11513446]

Qingyou Z, Junbao D, Chaoshu T. The efficacy of midodrine hydrochloride in the treatment of children with vasovagal syncope. J Pediatr. 2006; 149:777-780. [PubMed: 17137891]

Raj SR, Faris PD, McRae M, Sheldon RS. Rationale for the prevention of syncope trial IV: assessment of midodrine. Clin Auton Res. 2012; 22:275-280. [PubMed: 22610268]

Raj SR, Rose S, Ritchie D, Sheldon RS. The Second Prevention of Syncope Trial (POST II)-a randomized clinical trial of fludrocortisone for the prevention of neurally mediated syncope: rationale and study design. Am Heart J. 2006; 151:1186-1187. [PubMed: 16781217]

Raviele A, Brignole M, Sutton R, Alboni P, Giani P, Menozzi C, et al. Effect of etilefrine in preventing syncopal recurrence in patients with vasovagal syncope: a double-blind, randomized, placebo-controlled trial. The Vasovagal Syncope International Study. Circulation. 1999; 99:14521457. [PubMed: 10086969]

Romme JJ, van DN, Go-Schon IK, Reitsma JB, Wieling W. Effectiveness of midodrine treatment in patients with recurrent vasovagal syncope not responding to non-pharmacological treatment (STAND-trial). Europace. 2011; 13:1639-1647. [PubMed: 21752826]

Rose MS, Koshman ML, Spreng S, Sheldon R. The relationship between health-related quality of life and frequency of spells in patients with syncope. J Clin Epidemiol. 2000; 53:1209-1216. [PubMed: 11146266]

Salim MA, Di Sessa TG. Effectiveness of fludrocortisone and salt in preventing syncope recurrence in children: a double-blind, placebo-controlled, randomized trial. J Am Coll Cardiol. 2005; 45:484488. [PubMed: 15708690]

Scott WA, Pongiglione G, Bromberg BI, Schaffer MS, Deal BJ, Fish FA, et al. Randomized comparison of atenolol and fludrocortisone acetate in the treatment of pediatric neurally mediated syncope. Am J Cardiol. 1995; 76:400-402. [PubMed: 7639169]

SHARPEY-SCHAFER EP. Syncope. Br Med J. 1956; 1:506-509. [PubMed: 13293372]

Sheldon R, Connolly S, Rose S, Klingenheben T, Krahn A, Morillo C, et al. Prevention of Syncope Trial (POST): a randomized, placebo-controlled study of metoprolol in the prevention of vasovagal syncope. Circulation. 2006; 113:1164-1170. [PubMed: 16505178] 
Sheldon R, Killam S. Methodology of isoproterenol-tilt table testing in patients with syncope. J Am Coll Cardiol. 1992; 19:773-779. [PubMed: 1545073]

Sheldon R, Koshman ML, Wilson W, Kieser T, Rose S. Effect of dual-chamber pacing with automatic rate-drop sensing on recurrent neurally mediated syncope. Am J Cardiol. 1998; 81:158-162. [PubMed: 9591898]

Sheldon R, Morillo C, Krahn A. Management of vasovagal syncope: 2004. Expert Rev Cardiovasc Ther. 2004; 2:915-923. [PubMed: 15500436]

Sheldon R, Morillo C, Krahn A, Medina E, Talajic M, Kus T, et al. A randomized clinical trial of fludrocortisone for the prevention of vasovagal syncope (POST2). Can J Cardiol. 2011; 27(5):S335-S336.

Sheldon RS, Morillo CA, Klingenheben T, Krahn AD, Sheldon A, Rose MS. Age-dependent effect of beta-blockers in preventing vasovagal syncope. Circ Arrhythm Electrophysiol. 2012; 5:920-926. [PubMed: 22972872]

Sheldon RS, Ritchie D, McRae M, Raj S. Norepinephrine transport inhibition for treatment of vasovagal syncope. J Cardiovasc Electrophysiol. 2013; 24:799-803. [PubMed: 23444896]

Solbiati M, Sheldon R. Implantable Rhythm Devices in the Management of Syncope. Auton Neurosci. 2014

Soteriades ES, Evans JC, Larson MG, Chen MH, Chen L, Benjamin EJ, et al. Incidence and prognosis of syncope. N Engl J Med. 2002; 347:878-885. [PubMed: 12239256]

Sra JS, Murthy VS, Jazayeri MR, Shen YH, Troup PJ, Avitall B, et al. Use of intravenous esmolol to predict efficacy of oral beta-adrenergic blocker therapy in patients with neurocardiogenic syncope. J Am Coll Cardiol. 1992; 19:402-408. [PubMed: 1346266]

Tan MP, Newton JL, Chadwick TJ, Gray JC, Nath S, Parry SW. Home orthostatic training in vasovagal syncope modifies autonomic tone: results of a randomized, placebo-controlled pilot study. Europace. 2010; 12:240-246. [PubMed: 19919966]

Theodorakis GN, Leftheriotis D, Livanis EG, Flevari P, Karabela G, Aggelopoulou N, et al. Fluoxetine vs. propranolol in the treatment of vasovagal syncope: a prospective, randomized, placebocontrolled study. Europace. 2006; (8):193-198. [PubMed: 16627439]

van Dijk N, de Bruin IG, Gisolf J, de Bruin-Bon HA, Linzer M, van Lieshout JJ, et al. Hemodynamic effects of leg crossing and skeletal muscle tensing during free standing in patients with vasovagal syncope. J Appl Physiol. 2005; 98:584-590. [PubMed: 15475601]

van Dijk N, Quartieri F, Blanc JJ, Garcia-Civera R, Brignole M, Moya A, et al. Effectiveness of physical counterpressure maneuvers in preventing vasovagal syncope: the Physical Counterpressure Manoeuvres Trial (PC-Trial). J Am Coll Cardiol. 2006; 48:1652-1657. [PubMed: 17045903]

van Dijk N, Sprangers MA, Boer KR, Colman N, Wieling W, Linzer M. Quality of life within one year following presentation after transient loss of consciousness. Am J Cardiol. 2007; 100:672-676. [PubMed: 17697827]

Ward CR, Gray JC, Gilroy JJ, Kenny RA. Midodrine: a role in the management of neurocardiogenic syncope. Heart. 1998; 79:45-49. [PubMed: 9505918]

Waxman MB, Yao L, Cameron DA, Wald RW, Roseman J. Isoproterenol induction of vasodepressortype reaction in vasodepressor-prone persons. Am J Cardiol. 1989; 63:58-65. [PubMed: 2909160]

White WD, Sheldon RS, Ritchie DA. Learning needs of patients with vasovagal syncope. Can J Cardiovasc Nurs. 2003; 13:26-30. [PubMed: 12703103]

Zeng H, Ge K, Zhang W, Wang G, Guo L. The effect of orthostatic training in the prevention of vasovagal syncope and its influencing factors. Int Heart J. 2008; 49:707-712. [PubMed: 19075486] 


\section{Highlights}

- Non-pharmacological therapy is often effective in preventing vasovagal syncope

- Drugs may be needed in select patients only

- Education, hydration, and physical counter-measures are quite effective

- Midodrine and fludrocortisone are the primary drugs used for VVS 


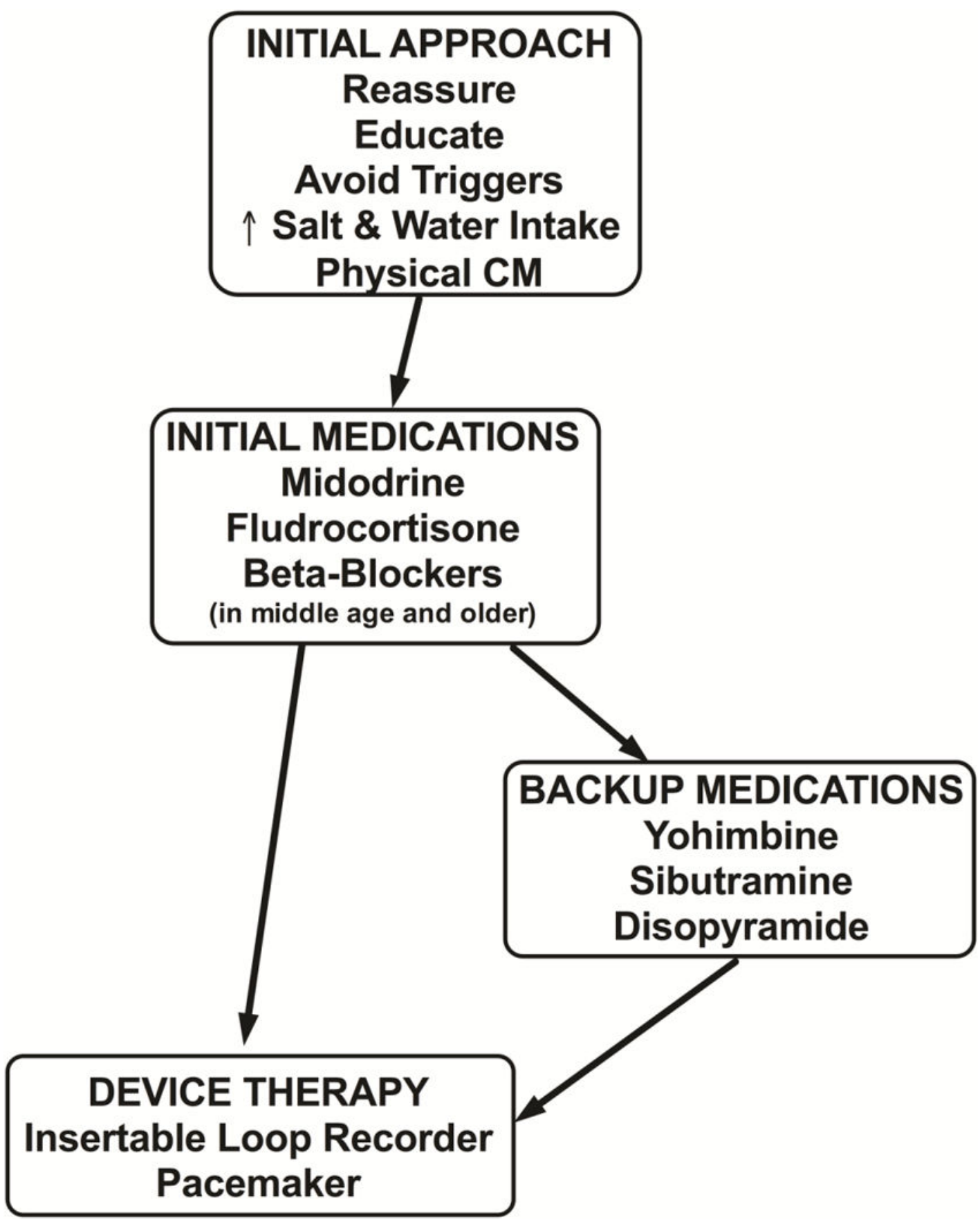

FIGURE 1. Treatment Approach for Vasovagal Syncope

Treatment algorithm for vasovagal syncope including education, lifestyle changes, physical maneuvers, medications, and implantable devices. Abbreviations: $\mathrm{CM}=$ countermeasures. 


\section{TABLE 1}

Non-pharmacologic Interventions for Vasovagal Syncope

\begin{tabular}{|c|c|c|}
\hline Treatment & Strength of Recommendation & Level of Evidence \\
\hline $\begin{array}{l}\text { Teaching about avoiding triggering situations } \\
\text { - } \quad \text { Standing still for long periods of time } \\
\text { - } \quad \text { Extreme temperatures (hot weather, hot showers) } \\
\text { - Straining during micturition/defecation } \\
\text { - } \quad \text { Fasting } \\
\text { - } \quad \text { Alcohol or vasodepressor drugs } \\
\text { - Sudden postural change } \\
\text { - Stressful situations and hyperventilation }\end{array}$ & & \\
\hline Increasing sodium and water intake to increase intravascular volume & Class IIa (Reasonable to Perform) & Level B \\
\hline \multicolumn{3}{|l|}{ Daily sodium intake of 10 grams for recurrent symptoms } \\
\hline \multicolumn{3}{|l|}{ Daily water intake of at least 2 liters } \\
\hline Discontinuing potentially offending medications & Class IIa (Reasonable to Perform) & Level C \\
\hline \multicolumn{3}{|l|}{ Diuretics, vasodilators, venodilators } \\
\hline Physical counter-maneuvers & Class IIa (Reasonable to Perform) & Level B \\
\hline \multicolumn{3}{|l|}{ Rapid supine positioning } \\
\hline \multicolumn{3}{|l|}{ Abdominal binders and elastic stockings } \\
\hline \multicolumn{3}{|l|}{ Tilt training } \\
\hline Inpatient tilt training & Class IIb (May Be Considered) & Level B \\
\hline Outpatient tilt training & Class III (No Benefit) & Level B \\
\hline
\end{tabular}

Strength of recommendation and level of evidence grading used the American College of Cardiology \& American Heart Association clinical practice guidelines guidance (Gibbons, Smith, \& Antman, 2003). 
TABLE 2

Pharmacologic Interventions for Vasovagal Syncope

\begin{tabular}{|c|c|c|}
\hline Treatment & Strength of Recommendation & Level of Evidence \\
\hline Increasing blood volume & & \\
\hline $\begin{array}{c}\text { Fludrocortisone } 0.1-0.2 \mathrm{mg} \text { daily } \\
\quad \text { especially in patients }<40 \text { years }\end{array}$ & Class IIa (Reasonable to Perform) & Level B \\
\hline Decreasing triggering increases in sympathetic tone & & \\
\hline $\begin{array}{c}\text { Metoprolol } 25-50 \text { mg twice per day } \\
\text { in patients <40 years }\end{array}$ & Class III (No Benefit) & Level A \\
\hline $\begin{array}{c}\text { Metoprolol 25-50 mg twice per day } \\
\text { in patients } \geq 40 \text { years }\end{array}$ & Class IIa (Reasonable to Perform) & Level B \\
\hline Increasing vascular tone & & \\
\hline Midodrine 2.5-10 mg every 4 hours for 3 doses per day & Class IIa (Reasonable to Perform) & Level B \\
\hline Coping with Recurrent Syncope & & \\
\hline Selective Serotonin Reuptake Inhibitors & Class IIb (May Be Considered) & Level B \\
\hline Rare use of other medications & & \\
\hline Disopyramide & Class IIb (May Be Considered) & Level C \\
\hline Yohimbine & Class IIb (May Be Considered) & Level C \\
\hline Sibutramine & & Level C \\
\hline
\end{tabular}

Strength of recommendation and level of evidence grading used the American College of Cardiology \& American Heart Association clinical practice guidelines guidance (Gibbons et al., 2003). 